\title{
Different Didactical Approaches Using a Remote Lab: Identification of Impact Factors
}

\author{
Natércia Lima, Clara Viegas, and Francisco José García-Peñalvo
}

\begin{abstract}
Conducting laboratory experiments is of vital importance in science and engineering education, independently the level of education. Nowadays, teachers have different ways of allowing students to develop these competences other than hands-on labs, such as simulations and remote labs. This study is focused on the combined use of the three resources, carried out by 51 teachers, in 25 different courses. In total, 39 didactical implementations in the electric and electronics area were performed in several Higher Educational Institutions and Secondary Schools, in Argentina and Brazil. This occurred during 2016 and 2017 academic years, under the scope of the VISIR+ project and VISIR was the implemented remote lab and reached 1569 students. Teachers' perception about student acceptance and performance with VISIR as well as teachers' satisfaction with VISIR, were cross analysed with course characteristics as well as didactical implementation design factors and several interesting correlations stood out: Teachers extra care in designing VISIR tasks accordingly to the learning outcomes/ competences they want their students to develop revealed as a crucial factor; Teacher experience with VISIR plays an important role in students' satisfaction with the tool; Teacher introduction and support to VISIR along the semester is also an important factor.
\end{abstract}

Index Terms-Educational activities, educational technology, engineering education, remote handling.

\section{INTRODUCTION}

A $\mathrm{T}$ THE end of their college education engineering students are expected to have a set of professional skills related to teamwork, oral and written communication, and impact of engineering solutions, life-longtearning and knowledge of contemporary issues [1], contributing to maintain and improve their countr's social well-being and economic prosperity. When making the transition to the labour market graduates need not only to have a solid theoretical-practical knowledge in their field of specialization, but also have appropriate soft or generic skills, such as communication, teamwork, time management, problem-solving, learning aptitude and the ability to manage stress or heavy workloads [2], [3]. Lab experiments allow students to efficiently apply theoretical concepts to practical situations, as well as handling instruments, equipment and data. This practice contributes to build and consolidate knowledge and competences [4]. Simulation and remote labs provide an alternative and/or complementary way to develop knowledge and competences being a "blended" or "hybrid" approach to laboratory learning - a combination of hands-on labs, simulation and remote labs - the most effective [5]. These online resources offer new learning spaces and have three main advantages: accessibility, availability and safety [6]. They allow teachers to diversify their classes in a simple way- they do not have to think if the lab is free and are suitable for classes with a lot of students. Likewise, they allow students to practice at their own pace, potentiating student' autonomous work, time management and responsibility [5], [7]. The use of these Information and Communication Technology (ICT) tools in lower levels of education (basic or secondary) are likely to appeal young students as they are a generation of digital natives [8]. This usage may help to reduce some of the apathy and fear students feel concerning science and contribute to scaffold Science, Technology, Engineering and Mathematics (STEM) courses.

While with simulations the results obtained are from computational models, with remote labs the results are real, as a remote lab is a real lab in which the user and the equipment/instruments are physically apart. To perform an experiment the user has to access the internet and control the physical parameters of the experiment, through a computer or smartphone interface [9]. Remote labs, being tools that combine virtual access and real experimental results, have the advantages of simulations and hands-on labs. Its disadvantage is the very limited ability to provide manual skills. Usually teachers do not need to do a huge effort to integrate these tools in the curriculum. Also the contextualization of the theoretical concepts can be easily achieved with remote labs, being quite powerful to address the nature of science and technology [10], [11], arising students' interest to learn the target topic. Remote labs potentiate education and collaboration between institutions, allowing sharing resources and didactical experiences [12]. On the other hand, they may also enhance students' interaction, cooperation, teamwork, communication and critical thinking as long as tasks using these resources are designed accordingly. Special attention should be given to it, considering the impact they have on student performance [13]. The groups or type and level of competences teachers expect 
their students to develop with these resources should be taken in to consideration in the task design [14]. It is important there is a perfect adjustment between the type/level of competence and the type of task, being the teacher mediation role fundamental to lead students in the process [14]. Characteristics such as giving students power of decision and keeping tasks challenging foster students' engagement as long as tasks purpose is clear to them [15].

In the electric and electronic circuit's topic, VISIR (Virtual Instrument Systems in Reality) is amongst the most used labs and was distinguished in 2015 as the best remote lab by the Global Online Laboratory Consortium (GOLC) Executive Committee [16]. It was created in 2004 by the Blekinge Institute of Technology (BTH) and can be considered a remote workbench with the same instruments and components that are available on a hands-on electric and electronic circuits lab, similar in all engineering schools [17]. Since then, several VISIR systems have been installed in Europe, India and Morocco [18] and more recently (2016 and 2017) in five Higher Education Institution (HEI) in Argentina and Brazil. The later have been installed in the scope of the VISIR+ Project [19]. The project intended to disseminate VISIR to these HEI in Latin America (LA) and some associate partners of theirs, sharing experiences with the European Partners (EP), installing VISIR systems and performing their own didactical implementations. One of the project's premises was the didactical implementations involved the use of several simultaneous resources: hands-on, simulation and remote lab VISIR as well as calculus and teachers tried to follow an Enquiry-Based Learning (EBL) Methodology, at some extent [20].

This work intends to be a step forward in understanding how VISIR can be used by teachers in their courses. It describes 39 didactical implementations that took place in numerous courses, several education levels, under different contexts and with different goals, during 2016 and 2017 academic years in several HEI and also some High Schools in Argentina and Brazil. These implementations involved 25 different courses, 51 teachers and 1569 students.

This paper is organized in five sections and its' aim is to study the characteristics of these 39 didactical implementations trying to identify success factors that impact in students' performance and motivation. Section II is devoted to the research methodology and includes a summary of the analyzed data and the main characteristics of the courses where the didactical implementations took place. Section III presents the results and in Section IV they are discussed. Finally, the conclusions arising from this work are presented in Section V.

This paper is an extended work of "Macro Analysis on how to Potentiate Experimental Competences Using VISIR", published in TEEM2018 [21]. It is a step forward the previous one, as not only more data is taking into account in the analysis, but also a much detailed and thoughtful analysis is carried on. The obtained results are also extensively discussed.

\section{Methodology}

VISIR is a valuable resource in engineering education [6], [18], [22], [23] and this work addresses a
TABLE I

CATEgorization OF THE ANALYSIS OF VISIR USAGE

\begin{tabular}{|c|c|c|}
\hline Dimensions & \multicolumn{2}{|l|}{ Categories } \\
\hline \multirow{12}{*}{ Design } & \multicolumn{2}{|c|}{ Course Implementation Edition } \\
\hline & \multicolumn{2}{|c|}{ VISIR Usage in Course Contents (\%) } \\
\hline & \multirow{2}{*}{ EBL Methodology } & Yes \\
\hline & & No \\
\hline & \multirow{2}{*}{ Resources Used } & Simulation \\
\hline & & Hands-on (number) \\
\hline & \multirow{3}{*}{ Tasks } & Number \\
\hline & & $\begin{array}{l}\text { Weight in final } \\
\text { grade }\end{array}$ \\
\hline & & Regime* \\
\hline & \multirow{3}{*}{$\begin{array}{l}\text { Competence Goal } \\
\text { Level }\end{array}$} & Level 1 \\
\hline & & Level 2 \\
\hline & & Level 3 \\
\hline & \multirow{2}{*}{ VISIR Introduction } & In class \\
\hline & & None \\
\hline & \multirow{3}{*}{ VISIR Use Level } & Basic \\
\hline & & Intermediate \\
\hline & & Advanced \\
\hline & \multirow{3}{*}{ VISIR Support } & Presential \\
\hline & & Email \\
\hline & & Support Material \\
\hline & \multirow[t]{2}{*}{ Implemented Tasks } & $\begin{array}{l}\text { Circuits } \\
\text { Assembling }\end{array}$ \\
\hline & & Circuits Design \\
\hline & \multicolumn{2}{|c|}{ Teachers Logs to VISIR } \\
\hline \multirow{3}{*}{ Teacher Perception } & \multicolumn{2}{|c|}{ Students Performance (VISIR tasks) } \\
\hline & \multicolumn{2}{|l|}{ Teacher Satisfaction } \\
\hline & \multicolumn{2}{|l|}{ External factors } \\
\hline
\end{tabular}

* If the tasks were in group or individual and if they were mandatory

macro-analysis involving 39 didactical implementations. Different approaches were used taking into account the country, level of education, course topic, course characteristics, resources used, learning goals and implemented tasks. The study is focused in each didactical implementation, their characteristics and teachers' usage and perception. Most courses just had one didactical implementation (one semester), but six of them undergone two editions (two semesters) and three of them three editions (three semesters) - in these situations, the evolution on consecutive editions was also analyzed. Considering the 39 VISIR didactical implementation done in different contexts, the research question tackled in this work is: "According to teachers' perception, which didactical implementation design factors seem to influence students' performance and motivation?"

\section{A. Research Methodology}

The analysis performed in this work relies on a multicase study research methodology [24]. Each case represents a different course where VISIR was implemented.

For each course, the dimensions and categories analysed are summarized in Table I. This analysis intends to characterize teacher's intentions while designing the VISIR implementation 
(Design), better understand how it was delivered (Implementation) and finally how did it result (only in terms of teacher's perception).

The competence goal level related to their work with VISIR teachers pursued when they stated their course learning objectives was categorized in three levels [14]:

- level 1: e.g. obtain data, measurements, establish the proposed experimental circuits, doing some calculus;

- level 2: e.g. analyse data, compare the differences between simulation data and real data, master experimental techniques, predict results, develop soft skills (team work, cooperation, communication);

- level 3: e.g. design/ plan the experiments; confront model data with the experimental; understand the differences between simulation data and real data, research skills, critical thinking.

This competence level will be analysed in terms of the teacher goal and in terms of the tasks proposed to students.

The VISIR usage within a Course ("VISIR Use Level") was categorized in three levels (Basic, Intermediate and Advanced) according to the type of use when compared to the course syllabus and its mapping in the degree. Basic level concerns to the use of basic instruments, measuring components, currents or voltages, Ohm's and Kirchhoff's laws. Intermediate level relates to 2nd level reasoning like use of non-linear components and analysis, circuits frequency response and transistors polarization. Finally, Advanced level corresponds to the use of VISIR with amplifiers (op-amps or transistor amplifiers) and other complex circuits.

A mixed analysis approach - quantitative and qualitative data - is used to analyse the 25 courses. Under the scope of the VISIR+ Project, a set of tools for collecting data was developed and validated [19]. In this work, we have used data collected from some of those tools: teachers pre and post implementation forms, educational modules and a teacher satisfaction questionnaire.

At the end of the course didactical implementation, the course head teacher was asked to fill up a satisfaction questionnaire composed by ten Likert questions, with four options (yes, often, sometimes, no) and a final open question asking for the main advantages/disadvantages of this resource. That questionnaire intended to evaluate teachers' satisfaction with VISIR, considering the didactical aspects as well as main advantages and disadvantages of the resource. The open questions were qualitatively analysed, following the procedure of the Grounded Theory [25]. The qualitative analysis on what the teachers report helped to build the analytical categories. Some teachers' interviews and informal comments were also registered.

Other analysed data consisted on the recordings of VISIR's system registering how many times (and when) teachers accessed it, detailed information about how VISIR was implemented on each course and teachers' opinion about students' performance.

\section{B. Case Studies Characteristics}

The courses' characteristics in which the VISIR didactical implementations occurred are briefly summarized in Table II
TABLE II

CASE STUdy Characteristics

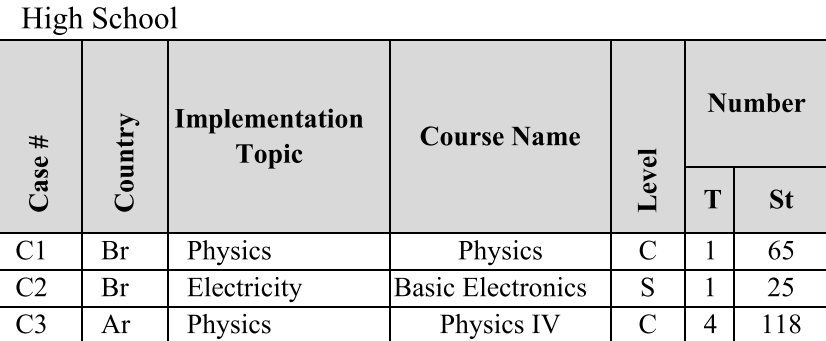

\begin{tabular}{|c|c|c|c|c|c|c|}
\hline \multirow{2}{*}{$\begin{array}{l}\# \\
\text { \# } \\
\tilde{U} \\
\tilde{U}\end{array}$} & \multirow{2}{*}{ 这 } & \multirow{2}{*}{$\begin{array}{c}\text { Implementation } \\
\text { Topic }\end{array}$} & \multirow{2}{*}{ Course Name } & \multirow{2}{*}{ ב্ّ } & \multicolumn{2}{|c|}{ Number } \\
\hline & & & & & $T$ & St \\
\hline $\mathrm{C} 4$ & $\mathrm{Br}$ & Electricity & Circuits Theory & $\mathrm{S}$ & 1 & 15 \\
\hline $\mathrm{C} 5$ & $\mathrm{Br}$ & Electricity & Electricity I & $\mathrm{S}$ & 3 & 164 \\
\hline C6 & $\mathrm{Br}$ & Electricity & Electricity II & $\mathrm{S}$ & 1 & 8 \\
\hline $\mathrm{C} 7$ & $\mathrm{Br}$ & Electricity & Instrumentation & $\mathrm{S}$ & 1 & 35 \\
\hline
\end{tabular}

Higher Education

\begin{tabular}{|c|c|c|c|c|c|c|}
\hline & & & & & & nber \\
\hline & & & & 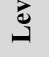 & $\mathbf{T}$ & St \\
\hline $\mathrm{C} 8$ & $\mathrm{Br}$ & Mathematics & Calculus IV & $\mathrm{C}$ & 1 & 124 \\
\hline $\mathrm{C9}$ & $\mathrm{Br}$ & Mathematics & $\begin{array}{l}\text { Probabilities } \\
\text { and Statistics }\end{array}$ & $\mathrm{C}$ & 1 & 84 \\
\hline $\mathrm{C} 10$ & $\mathrm{Br}$ & Electronics & Instrumentation I & $\mathrm{C}$ & 1 & 45 \\
\hline C11 & $\mathrm{Br}$ & Electricity & Circuits III & $\mathrm{S}$ & 1 & 19 \\
\hline $\mathrm{C} 12$ & $\mathrm{Br}$ & Electricity & Electronics II & $S$ & 1 & 18 \\
\hline $\mathrm{C} 13$ & $\mathrm{Br}$ & Electronics & $\begin{array}{c}\text { Amplifying } \\
\text { Structures }\end{array}$ & $S$ & 1 & 10 \\
\hline $\mathrm{C} 14$ & $\mathrm{Br}$ & Electricity & $\begin{array}{c}\text { Electric Circuits } \\
\text { Laboratory }\end{array}$ & $\mathrm{S}$ & 2 & 36 \\
\hline $\mathrm{C} 15$ & $\mathrm{Br}$ & Projects & $\begin{array}{l}\text { Engineering } \\
\text { Introduction }\end{array}$ & S & 4 & 20 \\
\hline $\mathrm{C} 16$ & $\mathrm{Br}$ & Electricity & \begin{tabular}{|c|}
$\begin{array}{c}\text { General Electricity } \\
\text { Laboratory }\end{array}$ \\
\end{tabular} & $\mathrm{C}$ & 4 & 442 \\
\hline $\mathrm{C} 17$ & $\mathrm{Br}$ & Electricity & \begin{tabular}{|c|} 
Electric and \\
Magnetic \\
Measurements \\
\end{tabular} & $\mathrm{S}$ & 2 & 50 \\
\hline $\mathrm{C} 18$ & $\mathrm{Br}$ & Electricity & Applied Electricity & $\mathrm{I}$ & 1 & 15 \\
\hline C19 & Ar & Electronics & $\begin{array}{c}\text { Physics of } \\
\text { Electronic Devices }\end{array}$ & $\mathrm{S}$ & 4 & 55 \\
\hline $\mathrm{C} 20$ & $\mathrm{Ar}$ & Electricity & Circuits Theory & $\mathrm{S}$ & 5 & 91 \\
\hline $\mathrm{C} 21$ & $\mathrm{Ar}$ & Electronics & $\begin{array}{c}\text { Devices \& } \\
\text { Electronic Circuits I }\end{array}$ & $\mathrm{S}$ & 7 & 60 \\
\hline $\mathrm{C} 22$ & $\mathrm{Ar}$ & Physics & Physics II & $\mathrm{S}$ & 3 & 41 \\
\hline $\mathrm{C} 23$ & $\mathrm{Ar}$ & Electronics & Electronics 2 & $\mathrm{~S}$ & 2 & 13 \\
\hline $\mathrm{C} 24$ & $\mathrm{Ar}$ & Electronics & Electronics 3 & $\mathrm{~S}$ & 2 & 8 \\
\hline $\mathrm{C} 25$ & $\mathrm{Ar}$ & Physics & Electronics 1 & $\mathrm{~S}$ & 2 & 8 \\
\hline
\end{tabular}

(split in three sub tables), by level of education: High School, Technological (post High School degrees, typical 2 years long) and Higher Education (HE). These tables include information about: country (Brazil (Br), Argentina (Ar)), implementation topic, course name, level regarding course contents (according to whether or not its contents is related to the degree scientific 
area (EE majors and other majors) if affirmative it will be distinguished between Scientific (S) for more advanced contents and Introductory (I) for basic contents of the scientific area); if not is considered Complementary (C), number of teachers $(\mathrm{T})$ involved and number of students $(\mathrm{St})$ enrolled in the course.

All implementations took place between the second semester of 2016 and the second semester of 2017. Several teachers were involved in more than one didactical implementation - so the total number of teachers of Table II (three sub tables) is higher than 51, which is the number of different teachers involved.

\section{RESULTS}

Teachers introduced and used VISIR in their courses, which varied significantly in contents and level of difficulty, being some of them introductory courses (students' first contact with electric circuits) and some advanced ones, taking into account the learning goals they wanted to achieve.

They developed tasks accordingly to the competences they wanted their students to develop. Table III summarizes some of these results, including the implementation edition number (of each course and each head teacher), the number of tasks involving VISIR as well as its contribution to the courses final grade (Q means that it counts as qualitative information) and if they were developed in groups and mandatory (they had to deliver the tasks involving VISIR to pass the course). It also includes the number of teacher VISIR logs/per task (teacher direct usage of the tool), including the task preparation phase and the support given along the semester. It is clear that this number shows a wide range of variability from 3 to $85 \operatorname{logs}$ per task. Considering the courses in which there was more than one implementation $(\mathrm{C} 3, \mathrm{C} 5, \mathrm{C} 8, \mathrm{C} 9, \mathrm{C} 10 \mathrm{C} 16, \mathrm{C} 17$ and $\mathrm{C} 19)$ the number of logs per tasks tends to diminish or be similar, from one implementation to the next. The only exception is for case $\mathrm{C} 5$.

\section{A. VISIR Design}

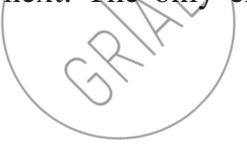

Teachers combined VISIR usage with other resources in the didactical implementation of their courses, but in some of them $(8 \%)$ VISIR was the only way for students to experiment with real equipment/instruments and components (Fig. 1). Still, the majority of teachers managed to use/implement simultaneously simulation, hands-on labs (in which the number of experiments ranged from one to twelve) and VISIR in their courses, allowing students to practice and develop competences in different manners.

The extent of VISIR usage in course contents (in \%) varied from 2 (a teacher simple experience in a very specific course topic) to $100 \%$, depending not only with course syllabus but also with teachers' goal and experience using VISIR. Still in most implementations the extent of VISIR usage in course contents was between 15 to $25 \%$. The majority (54\%) applied an EBL methodology in their courses at some extent.

The number of tasks involving VISIR varied between 1 and 4 . In terms of their weight contribution to final grade, in some Cases they were merely qualitative,
TABLE III

VISIR USAGE

\begin{tabular}{|c|c|c|c|c|c|c|c|c|}
\hline \multirow{2}{*}{$\begin{array}{l}\# \\
\text { \# } \\
\tilde{E} \\
\tilde{E}\end{array}$} & \multirow{2}{*}{ Course Name } & \multicolumn{2}{|c|}{$\begin{array}{l}\text { Edition } \\
\text { Number }\end{array}$} & \multicolumn{4}{|c|}{ Tasks } & \multirow{2}{*}{$\mathbf{L}$} \\
\hline & & $\mathrm{C}$ & $\mathbf{T}$ & $\mathbf{N}$ & W & $\mathbf{G}$ & M & \\
\hline $\mathrm{C} 1$ & $\begin{array}{l}\text { Physics } \\
\end{array}$ & 1 & 1 & 2 & $\mathrm{Q}$ & Yes & No & $\mathrm{Na}$ \\
\hline $\mathrm{C} 2$ & Basic Electronics & 1 & 1 & 1 & $\mathrm{Q}$ & No & No & $\mathrm{Na}$ \\
\hline \multirow{4}{*}{$\mathrm{C} 3$} & \multirow{4}{*}{ Physics IV } & 1 & 1 & 4 & $\mathrm{Q}$ & Yes & No & 4,8 \\
\hline & & 2 & 2 & 3 & $19 \%$ & Yes & Yes & 5,3 \\
\hline & & 2 & 1 & 3 & $19 \%$ & Yes & Yes & 4,7 \\
\hline & & 2 & 1 & 3 & $19 \%$ & Yes & Yes & 4 \\
\hline $\mathrm{C} 4$ & Circuits Theory & 1 & 1 & 1 & $\mathrm{Q}$ & $\mathrm{Na}$ & $\mathrm{Na}$ & $\mathrm{Na}$ \\
\hline \multirow{3}{*}{$\mathrm{C} 5$} & \multirow{3}{*}{ Electricity I } & 1 & 1 & 2 & $6 \%$ & No & No & $\mathrm{Na}$ \\
\hline & & 2 & 2 & 2 & $6 \%$ & No & No & 9,5 \\
\hline & & 3 & 3 & 2 & $6 \%$ & No & No & 18,5 \\
\hline C6 & Electricity II & 1 & 1 & 1 & $\mathrm{Q}$ & $\mathrm{Na}$ & No & $\mathrm{Na}$ \\
\hline C7 & $\begin{array}{c}\text { Instrumen } \\
\text { tation }\end{array}$ & 1 & 1 & 3 & Q & $\mathrm{Na}$ & No & 7 \\
\hline \multirow{3}{*}{$\mathrm{C} 8$} & \multirow{5}{*}{$\begin{array}{l}\text { Calculus IV } \\
\text { Probabilities } \\
\text { \&Statistics }\end{array}$} & 1 & 1 & 1 & $10 \%$ & Yes & No & 15 \\
\hline & & 2 & 2 & 1 & $11 \%$ & Yes & No & 25 \\
\hline & & 3 & 3 & 1 & $10 \%$ & Yes & No & 6,5 \\
\hline \multirow{2}{*}{ C9 } & & 1 & 1 & 1 & $11 \%$ & Yes & No & 12 \\
\hline & & 2 & 2 & 1 & $10 \%$ & Yes & No & 6,5 \\
\hline \multirow{2}{*}{$\mathrm{C} 10$} & \multirow{2}{*}{$\begin{array}{c}\text { Instrumen } \\
\text { tation I }\end{array}$} & 1 & 1 & 1 & $10 \%$ & Yes & No & 9 \\
\hline & & 2 & 2 & 1 & $10 \%$ & Yes & No & $\mathrm{Na}$ \\
\hline $\mathrm{C} 11$ & Circuits III & 1 & 1 & 2 & $5 \%$ & No & No & 15,5 \\
\hline C12 & Electronics II & 1 & 1 & 2 & $5 \%$ & No & No & 13,5 \\
\hline$\overline{\mathrm{C} 13}$ & $\begin{array}{l}\text { Amplifying } \\
\text { Structures }\end{array}$ & 1 & 1 & 3 & Q & $\mathrm{Na}$ & No & 10,7 \\
\hline C14 & $\begin{array}{c}\text { Electric Circuits } \\
\text { Laboratory }\end{array}$ & 1 & 1 & 3 & $15 \%$ & Yes & No & 7 \\
\hline $\mathrm{C} 15$ & $\begin{array}{l}\text { Engineering } \\
\text { Introduction }\end{array}$ & 1 & 1 & 4 & $27 \%$ & $\mathrm{Na}$ & Yes & 10,3 \\
\hline \multirow{2}{*}{$\mathrm{C} 16$} & \multirow{2}{*}{$\begin{array}{l}\text { General Electricity } \\
\text { Laboratory }\end{array}$} & 1 & 1 & 4 & $20 \%$ & Yes & No & 24,8 \\
\hline & & 2 & 2 & 4 & $20 \%$ & Yes & No & 20,8 \\
\hline \multirow{2}{*}{$\mathrm{C} 17$} & \multirow{2}{*}{$\begin{array}{c}\text { Electric \& } \\
\text { Magnetic } \\
\text { Measurements }\end{array}$} & 1 & 1 & 3 & $\mathrm{Na}$ & $\mathrm{Na}$ & $\mathrm{Na}$ & $\mathrm{Na}$ \\
\hline & & 2 & 2 & 2 & $\mathrm{Na}$ & $\mathrm{Na}$ & $\mathrm{Na}$ & $\mathrm{Na}$ \\
\hline $\mathrm{C} 18$ & Applied Electricity & 1 & 1 & $\begin{array}{l}\mathrm{N} \\
\mathrm{a}\end{array}$ & $\mathrm{Na}$ & $\mathrm{Na}$ & $\mathrm{Na}$ & $\mathrm{Na}$ \\
\hline \multirow{3}{*}{$\mathrm{C} 19$} & \multirow{3}{*}{$\begin{array}{c}\text { Physics of } \\
\text { Electronic Devices }\end{array}$} & 1 & 1 & 1 & $\mathrm{Q}$ & No & No & 6 \\
\hline & & 2 & 2 & 1 & $\mathrm{Q}$ & No & Yes & 8 \\
\hline & & 3 & 3 & 1 & $\mathrm{Q}$ & No & Yes & 9 \\
\hline \multirow{2}{*}{$\mathrm{C} 20$} & \multirow{2}{*}{ Circuits Theory } & 1 & 1 & 1 & $\mathrm{Q}$ & Yes & Yes & 85 \\
\hline & & 2 & 2 & 1 & $\mathrm{Q}$ & Yes & Yes & 3 \\
\hline $\mathrm{C} 21$ & $\begin{array}{c}\text { Devices \& } \\
\text { Electronic Circuits I }\end{array}$ & 1 & 1 & 1 & Q & No & No & 12 \\
\hline $\mathrm{C} 22$ & Physics II & 1 & 1 & 1 & $\mathrm{Q}$ & No & No & $\mathrm{Na}$ \\
\hline $\mathrm{C} 23$ & Electronics 2 & 1 & 1 & 2 & $5 \%$ & No & Yes & 21,8 \\
\hline $\mathrm{C} 24$ & Electronics 3 & 1 & 1 & 2 & $5 \%$ & No & Yes & 12,8 \\
\hline $\mathrm{C} 25$ & Electronics 1 & 1 & 2 & 2 & $\mathrm{Q}$ & No & Yes & 10 \\
\hline
\end{tabular}

Legend: C- Course; T- Teacher; N- Number; W- Weight; G - Group?; M- Mandatory?; L - Number of Teachers Logs per Task.

others varied from 5 to $27 \%$ weight. This happened regardless the level of education. In $44 \%$ of the implementations the proposed tasks were to be developed in group, allowing students, the opportunity and time to discuss their ideas and communicate with others - high school teachers (except in case $\mathrm{C} 2$ ) opted for it. In 33\%, the tasks were individual, and for the remaining $23 \%$, there were no information. Just $28 \%$ 


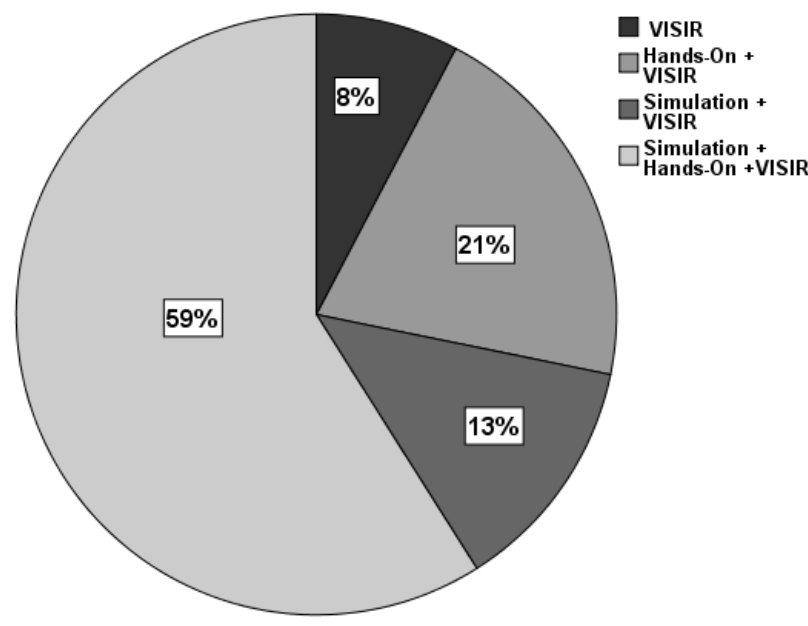

Fig. 1. Resources used in the implementations.

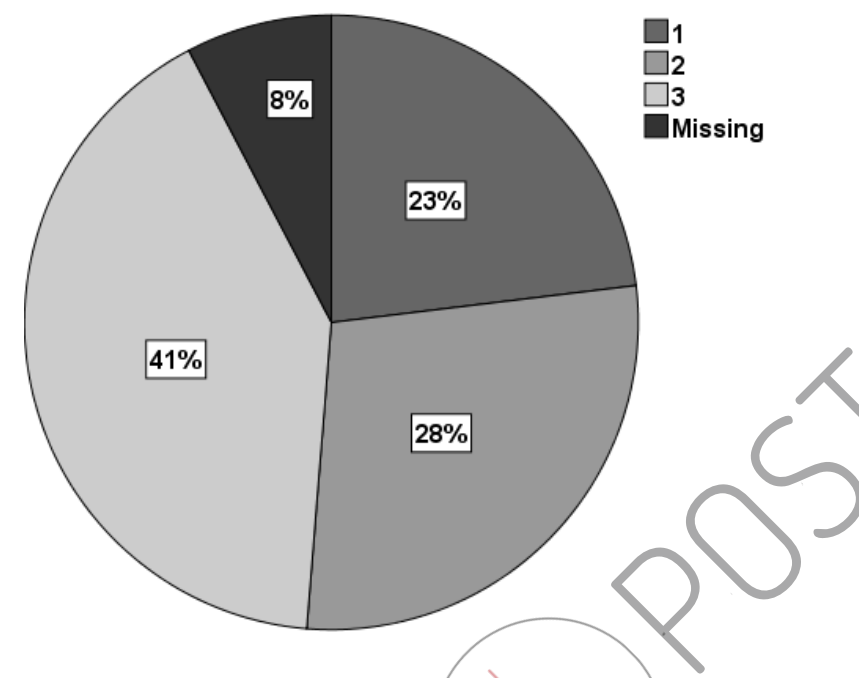

Fig. 2. Level of competence teachers wanted students to develop.

of the Cases opted for mandatory task(s) involying VISIR (in order to be able to be approved in the course).

The level of competence teachers wanted students to develop with the tasks involving VISIR is described in Fig. 2 and the connection between the level to the type of competence teachers identified was already described in Section II-A.

In all high school Cases (except partially in the second course edition of Case C3) and technological course implementations, teachers wanted their students to develop essential experimental competences (establish the proposed circuits and do some measurements and obtain data) and do some calculus while allowing the students to know and use several resources (level 1) and in some Cases they wanted them to develop analysis competences (analyze and compare the data obtained using the different resources) and some soft skills (level 2).

In $41 \%$ of the didactical implementations, teachers wanted students to develop higher order competences (level 3) - all of these (except partially in the second course edition of case C3) are higher education course implementations. In all, these teachers wanted students to develop critical analysis and the

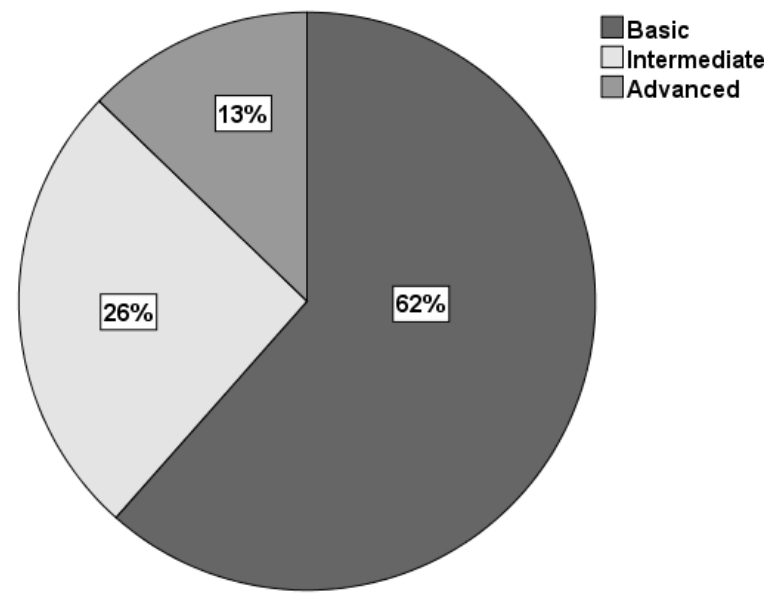

Fig. 3. VISIR Use on course contents level.

ability of problem solving. So, they proposed tasks in which students had to confront model data with real data and explain its differences. In case $\mathrm{C} 13$ teacher also wanted students to implement/design the circuits autonomously accordingly to a previously proposed problem.

\section{B. VISIR Implementation}

Teacher introduction to VISIR was mainly done in class by teachers - in 22 out of the 39 implementations, teachers decided to introduce VISIR in a class explaining the basics of the tool and doing some assembling and measurements (students have a role of observers). In 12 implementations teachers have introduced it in classes, but while they were explaining VISIR and doing some assembling and electric parameters measurements, students were doing the same in their own computers, trying it by themselves (students have a participant role). In 3 implementations (one of the $\mathrm{C} 3$ and $\mathrm{C} 8$ course implementation editions and case C13) teachers did not perform any introduction to VISIR - in C3 and C13 students were supposed to use the support material available and explore the tool, by themselves; in C3, although there was not a formal activity to introduce VISIR, the tasks involving VISIR were develop during class time. And for 2 of them it was not possible to have that information.

Considering VISIR support along the semester, although it is trusted that teachers accompanied students in their work with VISIR, we do not have the precise way how this support was carried out for $28 \%$ of the implementations. In some, teachers opted to answer students' doubts via email (15\%) or by uploading specific support material (33\%), such as tutorial videos or documents, in the Course Learning Management System (LMS). For the remaining, the tasks were fully performed during regular class time or at least partially performed in extra class time - all high school and technological course implementations, except case C6 (doubts via email and a written doc in LMS) are in this category (teacher full support). VISIR usage on course contents level, categorized in three levels (Basic, Intermediate and Advanced) as described in section II.B is displayed in Fig. 3. Only in 5 cases the 
level was Advanced (all higher education advanced courses); 10 performed didactical implementations of an intermediate level (higher education courses). But for the majority (24) the level was Basic (some higher education courses and all high school and technological course implementations lie in this category).

Mainly, VISIR allows three types of didactical setups depending on the allowed level of students' autonomy while performing the tasks. So, while designing the VISIR tasks teachers can opt from:

- pre-designed circuit, where teachers do all the setups: students' interaction with the tool is minimal as all the connections were already performed by the teacher and students just perform the measurements;

- pre-defined circuit, where students design the circuit on their own, making the connection and the measurements (similar to the experience they do in the hands-on lab), but they have access to a restricted number of components previously defined by the teacher;

- non-defined circuit, where students have freedom to fully design the circuits - they can choose components, add components, and make all connections with the measurement equipment, solving autonomously the proposed tasks.

Just in one Case (C13) the teacher opted for non-defined circuits. The remaining chose pre-defined circuits.

In 12 implementations the VISIR tasks consisted of doing some circuits assembling and some parameters (such as current and voltage) measurements (Task type 1) (all high school and technological course implementations opted for it, except C1, C4 and C7). In 23 implementations, the tasks were more ambitious. In addition to circuits assembling and some parameters measurements students were supposed to compare those results with the theoretical expected results $(\mathrm{Cl}, \mathrm{C} 4$ and C7) and/or results obtained with other resources: simulation and/or hands-on (Task type 2). This dast category covers only higher education course implenentation, although not all higher education teachers opted for this type of task in their courses - some of them opted for the simpler one (task type 1). In Case $\mathrm{C} 13$, the teacher was determined that students had to design a circuit to solve a specific problem and then compare the results with the theoretical ones as well as with the results obtained with simulation and hands-on lab (Task type 3). For 3 implementations it was not possible to have information about the type of tasks teachers proposed.

\section{Teacher Perception}

Teacher perception about students' acceptance and performance with VISIR, which reflects students' satisfaction with the tool was split it in 4 levels of hierarchy (from 1 to 4) (Fig. 4) and the results show the majority were motivated. Just in Cases C11 and C14 teachers reported students had difficulties and/or disliked (level 1) the tool. In Cases C23, C24 and C25 teachers stated students accomplished the task goals without difficulties (level 2), solving the proposed issues/problems. In the majority, teachers testified students were highly motivated, challenged and enthusiastic with the

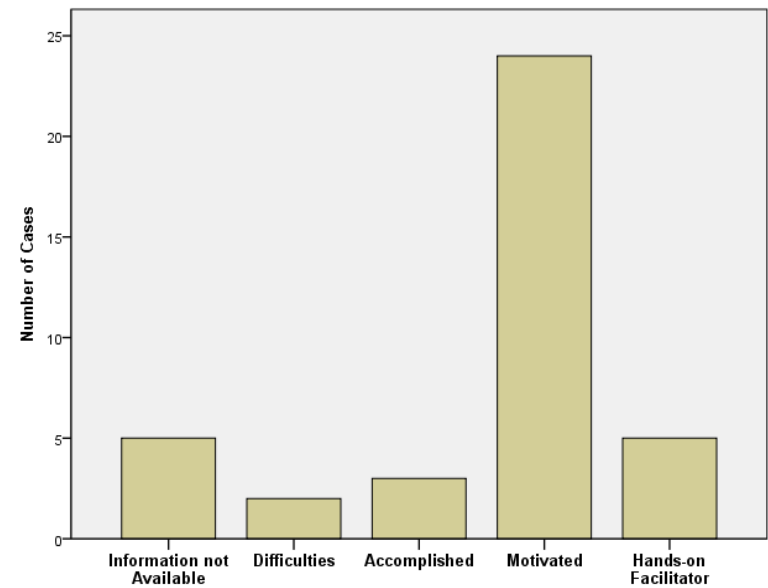

Fig. 4. Teachers' perception of student's satisfaction with VISIR.

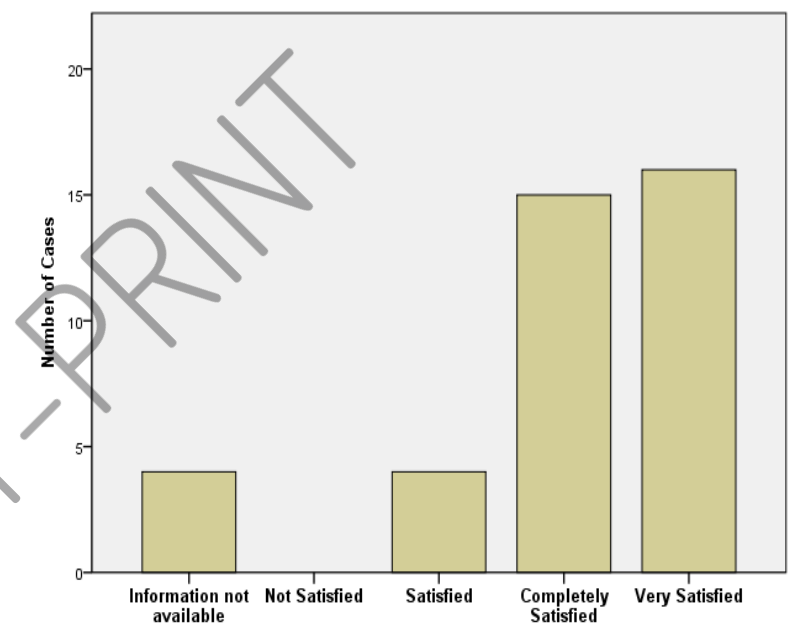

Fig. 5. Teachers satisfaction with VISIR.

tool, (level 3) which naturally lead to a good performance with it. In Cases C5 (in the three course editions), C7 and C10 (second implementation) teachers commented that after using VISIR, students felt much more at ease in the hands-on lab, being faster and performing less mistakes (level 4).

Regarding the "teacher satisfaction with VISIR", a quantitative analysis of the teachers' satisfaction questionnaire was carried out, splitting in 4 levels of hierarchy (from 1-less satisfied to 4-most satisfied). The results are displayed in Fig. 5. None fit in level 1 (not satisfied). In 10\%, representing 4 implementations (Cases $\mathrm{C} 4, \mathrm{C} 11$ and $\mathrm{C} 15$ and one of the implementations of $\mathrm{C} 3$ ) teachers felt satisfied with the tool. This analysis also pointed out that in $62 \%$ of the implementations teachers considered that the use of VISIR (along with other resources) contributed to the increase of the calculus exercises performed by students.

A qualitative analysis of the open questions of the teachers' satisfaction questionnaire was also carried out. The point was to identify the main ideas (besides different linguistic formulations) for each teacher, which would represent the categories in the analysis. So, what is important is not the number of teachers/answers, but the opinions expressed - semantic 
TABLE IV

OPEN QUESTION QUALITY ASSESSMENT (POSITIVE AND Negative FACTORS (IN SHADOW)

Factors (positive/negative)

\begin{tabular}{|c|c|c|}
\hline \multirow{10}{*}{ 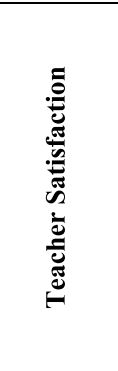 } & Increase students practice & 31 \\
\hline & Increase students motivation & 8 \\
\hline & Diversify teaching methods & 9 \\
\hline & Increase teacher autonomy & 3 \\
\hline & Cost Free & 3 \\
\hline & Damage Free & 3 \\
\hline & Configuration Issues & 6 \\
\hline & Instability & 3 \\
\hline & Interface old fashionable/too simple & 2 \\
\hline & Teachers experience with tool required & 2 \\
\hline \multirow{2}{*}{$\begin{array}{l}\text { External } \\
\text { Factors }\end{array}$} & Problems with Internet & 7 \\
\hline & $\begin{array}{l}\text { Computers and/or Computer room not } \\
\text { adequate /available }\end{array}$ & 5 \\
\hline \multicolumn{2}{|c|}{ Nothing negative to highlight } & 10 \\
\hline
\end{tabular}

clusters within responses, given the teachers expressed opinions, in spite of the minor variants with which they were formulated or the internal aspects to which they refer [25].

According to teachers' identification about VISIR main advantages and disadvantages (What advantages and disadvantages do you find in the use of VISIR?) this qualitative assessment of the open answers allowed the identification of 10 factors, considering directly Teacher Satisfaction: 6 positive and 4 negative (Table IV). It was also included the category External Factor to account for teachers' comments that influenced teacher satisfaction with the tool but were due to factors not directly related to VISIR. Some teachers considered there was no negative factor about VISIR and in view of its importance it was also considered.

The results highlight teachers consider WISIR a valuable resource. The most positive referred faetor was that allowed to increase student practice. The most negative factor was configuration issues, related to specific aspects about VISIR functioning.

\section{Didactical Implementation Iterations}

Considering the courses in which there was more than one implementation (C3, C5, C8, C9, C10, C16, C17 and C19), in the majority of Cases, there were no significant changes in the subsequent course editions. But in some Cases, for different reasons teachers felt the need to introduce changes in the implementation.

That was the case of C3 course implementation. In its first edition, VISIR weight in final grade was only qualitative and the proposed VISIR tasks were not mandatory (to pass the course). The teacher implemented 4 tasks using VISIR, being the remote lab the only way for students to experiment with real equipment/instruments and develop experimental competences. In its second edition, C3 course occurred simultaneously in 3 different degrees, with the same team of teachers for all of them, remaining the head teacher of the first course edition in one of them. This teacher got familiarized with the tool and perceiving its advantages not only used it again but persuaded other teachers to use it and gave them support. From the first course implementation to the second, VISIR weight in the final grade gained considerable importance (19\%). Although the number of VISIR tasks was reduced from 4 to 3 , the tasks became mandatory to pass the course and they used combinations of the resources: not only the remote lab VISIR, but also hands-on lab and simulation.

In case $\mathrm{C} 5$, the three course editions were implemented the same way. Accordingly to the teacher, these technological degree students initiate this first semester course with many difficulties not only in mathematics but also in reasoning organization, leading to high numbers of dropouts and failures. However, students' acceptance and performance with VISIR was really good (level 4) - teacher stated "VISIR motivated students (those who tried it), helping them in the comprehension of the operation of the breadboard and instrument connections, especially for current measurement. It is an important aid tool also for the hands-on lab: students were more at ease, spending less time assembling the circuits and doing less mistakes".

In case C8, the teacher tried several different ways of introducing VISIR to his students and, after 3 implementations, considered that for his case (use of VISIR for contextualization of mathematical concepts) it would be best to introduce it briefly in class (teacher expositive presentation) and simultaneously deliver a tutorial video in LMS, guiding students in the VISIR circuits' assembling. Teacher found VISIR so interesting for mathematical contextualization that he decided to use it in other Math's course (C9) in a similar way. Considering more closely the guidelines of VISIR + project, in $\mathrm{C} 9$, he involved the use of simultaneous resources and implemented a handson simple task. The type of VISIR task was also changed, becoming a group task. Teacher considered "It was a huge advantage to have access to an actual lab (VISIR) during these rather theoretical math courses".

In case $\mathrm{C} 10$, although there were no differences from the first to the second implementation, teacher's perception about students' performance with VISIR increased from level 3 to level 4. Accordingly to teacher's opinion, this might be linked to his experience with the tool and the number of students in the second course edition (14) being less than in the first one $(31)$ - in the second implementation, teacher not only had more experience with the tool but also had more time for each student.

In case $\mathrm{C} 19$, there were several differences from the first edition to the subsequent ones. The VISIR usage in course contents increased from $6 \%$ in the first edition to $25 \%$ in the second and third editions. This increase went along with a change in VISIR support along the semester - in the first edition teachers just uploaded a written doc in the course LMS page and in the subsequent ones they also answered student doubts via email. The task also became mandatory to pass the course.

For Case C16 and C17 there was no change from the first to second edition, although in $\mathrm{C} 17$ we lack some pieces of information. 


\section{Discussion}

These 39 didactical implementations, embrace 25 courses, with different characteristics such as context, implementation topic, course contents level, VISIR use level, used resources, number, type and regime of proposed tasks.

Considering the 8 Cases in which there was more than one implementation (C3, C5, C8, C9, C10, C16, C17 and C19) it was supposed that if it was done by the same teacher, the number of logs per tasks would naturally diminish, as the teacher was already familiarized with the tool. Eventually if the teacher makes significant changes in the VISIR implementation in the successive course editions, this number may remain the same or even slightly increase. That was the case for all of them, except case C5 - the first two implementations were performed using a VISIR system from one of the EP, as their own system was not already been installed. In the 3rd implementation they used their own VISIR system, which implied some adjustments and mounting the experiments on the system.

In the courses in which there was more than one implementation, it is clear that as teachers got more familiarized with VISIR, they reinforced its usage in the subsequent course editions, trying to take the most of it. It is also perceptible that teachers reinforce their attention considering VISIR introduction as well as the provided support during the semester. This shows teachers are highly satisfied with the potential of the remote lab and adapt its usage accordingly to the type of course, students background and education level.

In fact, considering the variable "teacher satisfaction with VISIR", all these implementations (except one of the second editions of case C3 that fits in the category Satisfied) lie in the categories Very Satisfied (C3 first edition and one of the second editions, C5 and C16) and Completely Satisfied (one of the second editions of C3, C8, C9, C10 and C19); that information is not available for C17, C3 Case is quite curious. The head teacher of the first edition went from Very Satisfied to Completely Satisfied in the second edition. For the other two teachers, the second course edition was their first time with VISIR - one of them was Very Satisfied with the tool while the other was just Satisfied. This teacher did not find VISIR user friendly which contributed to decreasing his level of satisfaction.

In all one edition courses it was teachers' first experience with VISIR. Several teachers expressed their will to keep on using VISIR during the following academic year, which endorses teacher satisfaction with the tool. Still, Cases C4, $\mathrm{C} 11$ and $\mathrm{C} 15$ lie in the category Satisfied. In Case C4, although teacher made a very punctual use of VISIR, he was not familiarized with VISIR+ Project nor its tools, which may have contributed to a lower level of satisfaction - in fact important data for that implementation is missing. For Case C11, students' performance with VISIR lie in level 1 (difficulties) - students disliked VISIR and experienced difficulties in its usage and the majority failed the course - which may affect teacher satisfaction. Case C15 is quite a unique first semester course, completely based in hands-on projects (with the aid of several resources, including remote labs) with the aim of "showing Engineering to students". VISIR was just one more remote lab and probably arouse no special enthusiasm.

The number of teacher logs per task changes considerably amongst the different implementations, regardless implementation topic, course contents level or type of task. It is not clear which are the factors that influence this variation since it shows no correlations with any analysed aspect.

Teacher mediation in class and support/feedback in the proposed tasks also proves to play an important role in students' engagement with the tool and ultimately its success, which is in accordance with literature [26]. While using a new tool like VISIR, teachers' enthusiasm and familiarity (teachers own usage) is crucial, not only to arouse student perception of its utility, but also to stimulate their enthusiasm and will to use it, as some students may be reluctant to use it and/ or may experience some difficulties in the beginning. Teachers should be aware of it and be prepared to help students overcome these initial difficulties, quickly enough to avoid their disappointment. In fact, teachers' attention to VISIR - introduction and support during the tasks - plays a crucial role in students' engagement as it was already reported in literature [6], [18]. This support contributes not only to students' satisfaction with the tool, but also helps them to understand the usefulness of the resource, motivating its usage [27].

We wanted to determine if there was a correlation between teacher perception of students' satisfaction (acceptance and performance) with VISIR and teacher satisfaction with VISIR with:

- some general characteristics: country, level of education, students age, number of students and teachers involved;

- course design: course (and head teacher) implementation edition, VISIR usage in course contents, EBL Methodology usage, resources used, number of tasks and weight in final grade, regime of the task (in group or individual and if it was or not mandatory) and competence goal level.

- the way VISIR was implemented in the course including: VISIR introduction, VISIR support, VISIR use level, type of task and teacher $\log s$ to VISIR.

It was used Spearman correlation [28] to determine whether there was a correlation, considering each categorical variables (factors) with students and teacher satisfaction with VISIR (test variables). The correlations found between each test variable and the considered factors are displayed in Table V and Table VI. There are some correlations between some course/implementation characteristics with students and teacher satisfaction with VISIR.

Starting with students' satisfaction (acceptance and performance) with VISIR, the negative correlation between the level of satisfaction and the type of education points to students from lower levels of education achieving higher levels of satisfaction. In fact, high school students are not used to remote labs (or in some cases, nor to hands-on labs), so naturally they got more aroused and enthusiastic with VISIR. HEI usually have more available resources. A moderate negative correlation was also found with the competence level using VISIR, which might indicate when the tasks are more challenging, requiring students not only a bigger 
TABLE V

Correlations Between Teacher Perception About STUDENTS' SATISFACTION WITH VISIR AND IMPLEMENTATION CHARACTERISTICS

\begin{tabular}{|l|l|}
\hline & $\begin{array}{l}\text { Level of students acceptance } \\
\text { and performance with VISIR }\end{array}$ \\
\hline $\begin{array}{l}\text { Level of Education (High } \\
\text { School/Technological/HE) }\end{array}$ & $\mathrm{R}_{\mathrm{SP}}=-0,413^{*}(\mathrm{p}=0,015)$ \\
\hline $\begin{array}{l}\text { Competence Goal Level } \\
\text { using VISIR }\end{array}$ & $\left.\mathrm{R}_{\mathrm{SP}}=-0,513^{* *}(\mathrm{p}<0,001)\right)$ \\
\hline $\begin{array}{l}\text { Number of Course } \\
\text { Implementation Edition }\end{array}$ & $\mathrm{R}_{\mathrm{SP}}=0,344^{*}(\mathrm{p}=0,047)$ \\
\hline Number of students & $\mathrm{R}_{\mathrm{SP}}=0,367^{*}(\mathrm{p}=0,033)$ \\
\hline
\end{tabular}

TABLE VI

Correlations BetweEn TEACHER SATISFACTION With VISIR AND IMPLEMENTATION CHARACTERISTICS

\begin{tabular}{|l|l|}
\hline & $\begin{array}{l}\text { Teacher satisfaction level } \\
\text { with VISIR }\end{array}$ \\
\hline $\begin{array}{l}\text { Level of Education (High } \\
\text { School/Technological/HE) }\end{array}$ & $\mathrm{R}_{\mathrm{SP}}=0,391^{*}(\mathrm{p}=0,02)$ \\
\hline $\begin{array}{l}\text { Number of Tasks involving } \\
\text { VISIR }\end{array}$ & $\mathrm{R}_{\mathrm{SP}}=-0,516^{* *}(\mathrm{p}=0,002)$ \\
\hline
\end{tabular}

effort and time to complete them but also more knowledge, critical thinking and research skills, their levels of satisfaction unsurprisingly decrease. In fact, when the level of requirement considerably increases, the majority of students tends to lose interest. A weak correlation was found with the number of course implementation edition - as the course undergoes several implementations, teachers are more at ease with VISIR, and eventually had the opportunity to do some adjustments, accordingly to their perception of what it works best for their course. Teacher experience leads to higher levels of satisfaction. The number of students enrolled in the course is also (weak) correlated with students' satisfaction. The number of students in each course presents a wide variability from 8 to 442 students. Additionally, in courses with lower number of students, the majority is repeating the course - this may, somehow, mislead the results. Nevertheless, the result may point out that a minimum number of students is preferred to assure an interesting dynamic in class and collaborative work between peers [29].

Teacher satisfaction level with VISIR (Table VI) presents a moderate correlation with the level of education. This seems to denote VISIR usage is best accepted by HE teachers than from teachers from lower levels of education. Teacher satisfaction shows a negative moderate correlation with the number of tasks involving VISIR. This is perfectly plausible as the increase in the number of tasks will force teachers to a harder effort to accomplish and support it.

In this study, it was not found any association between teacher' introduction and support to VISIR to the level of student' acceptance and performance with it (accordingly

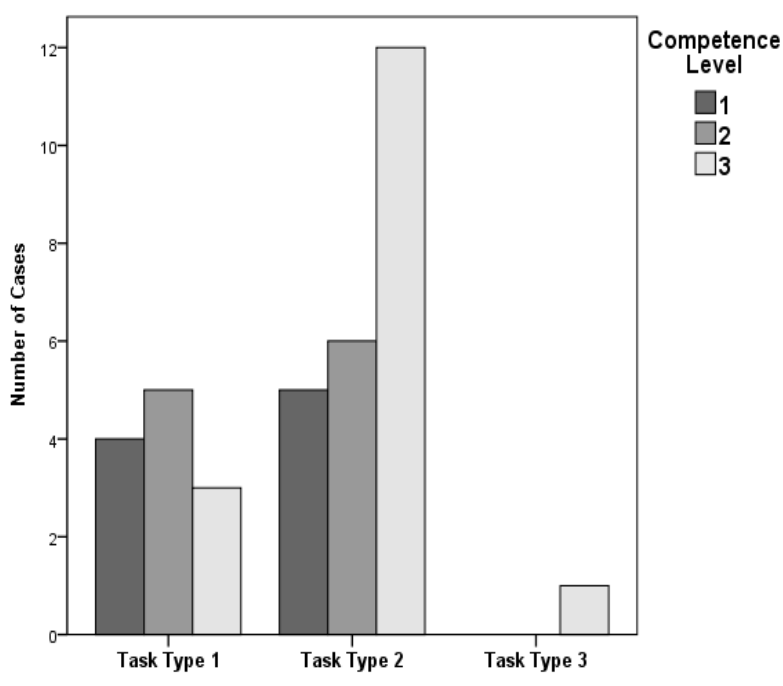

Fig. 6. Competence level/type of task.

to teachers' perception). This result seems consistent with the effort teachers did in VISIR introduction - all teachers organized activities to introduce it in class, except for one of the $\mathrm{C} 3$ and $\mathrm{C} 8$ course implementation editions and case C13. Still, although in one of the $\mathrm{C} 3$ course implementations there was not a formal VISIR introduction, the tasks involving VISIR were performed during class time, so with full teacher support. In case $\mathrm{C} 8$ teacher tried different ways of introducing VISIR, trying to figure out which one was more adequate to his context. But, although in one of the implementation editions, he did not plan any activity to introduce it, he prepared a detailed tutorial video, guiding students to the circuits they had to prepare. In the subsequent edition, he already introduced VISIR in class, as he realized it worked better for his case. Case C13 is an advanced course in the electronics area, so students are already very familiarized with circuits' components, equipment and measurements. Teacher considered, at this point, students were able to explore VISIR by themselves. Still he prepared a written document to guide them.

Besides teacher introduction to VISIR, teachers also developed different ways to support students during the semester: answering doubts via email, preparing tutorial videos or documents. In the lower levels of education by performing the tasks during class time.

As already discussed in literature [6], [18], [22], it is crucial teachers design the tasks involving VISIR accordingly to the learning outcomes they want their students to achieve and the level/type of competences they want them to develop. In this study teachers developed essentially three types of tasks, described in Section III-B. Using crosstabs (relation between two categorical variables) it was analysed if the type of task was in accordance with the level/type of competence teachers wanted their students to develop (Fig. 6). In some cases, there is a mismatch between the level of competence teachers wanted students to develop and the type of task they implemented.

When developing the Task type 1 (doing some circuits assembling and some parameters measurements) teachers are 
proposing to students' level 1 competences achievements and eventually depending on the task details (developed in groups, requires a written report) some soft skills (level 2). The Task type 2 (tasks in which circuits assembling and parameters measurements are required, and students were supposed to compare these results with the theoretical expected values and the results obtained with other resources) clearly may develop competences from level 1 and 2 and eventually level 3, depending upon the type of analysis required.

Still as we can observe in Fig. 6, with the Task type 1, teachers planned to develop not only level 1 competences but also level 2 and 3 competences. Teachers, while designing the Task type 2, also included the development of level 3 competences.

Several courses had several editions with the same teachers indicating teachers appreciated the resource. Teachers identified much more positive factors than negative factors when expressing their opinion about VISIR (Table IV); in fact, in 10 implementations teachers did not mention any negative factor. The most mentioned positives factors were increase students practice and motivation and diversify teaching methods. The negative ones were some configuration issues and system instability. Teachers also mentioned 2 more negative factors: they needed time to learn how to use the tool - being a new tool teachers need to spend some time to gain the knowledge and confidence to use it and help students overcame their initial difficulties; the interface is old fashionable / too simple VISIR was launched in 2004 and although during this period it has undergone some changes and updates, the interface may be considered a little old fashionable for this generation of digital natives, as was already reported in previous works [18], [27], [30]. An external factor, which may compromise teacher satisfaction and usage of the tool was also identified: computers and/or computer room not adequate/available.

\section{CONCLUSION}

The main goal of this work was to deeply analyse the characteristics of these 39 didactical implementations trying to identify success factors that, accordingly to teachers perception, impact in students' performance and motivation.

While analyzing the data from these courses' implementation results, some interesting factors emerge. The number of teacher logs per task differs substantially in the different implementations and it would be interesting, in a future work, try to explore the factors that may contribute to this variation. Factors like: teachers' background and experience in electric and electronic circuits' area, teachers' sensitivity to this type of resource and the support teachers have (or not) in the task preparation phase (in some HEI there is technical staff that can implement the circuits in the VISIR system while in others is the teacher that has that responsibility) may affect this number.

In the courses in which there was more than one implementation, it is clear that as teachers got more familiarized with VISIR, they reinforced its usage in the subsequent course editions, trying to take the most of it. These evidence teachers are highly satisfied with the remote lab and its potentialities.

According to teachers' perception, students' satisfaction (acceptance and performance) with VISIR is higher at lower levels of education, although this level of satisfaction decreases with the complexity of the proposed tasks. Students tend to achieve higher levels of satisfaction in courses that have undergone several implementations - teachers experience and familiarization with VISIR plays an important role.

Teachers satisfaction with VISIR is higher for higher levels of education. On the other hand, students' satisfaction with VISIR according to teachers' perception is superior at lower levels of education. That is, according to teachers, VISIR would be more suitable in higher levels of education, but they percept students from lower levels are more satisfied with it. However, this last variable is exclusively based on teacher perception and not the direct opinion of the students. Future work considering students' results will be considered in order to further assess this result. Teachers level of satisfaction diminishes with the rise of the number of tasks. The attention and effort teacher has to dedicate may be too much, compromising teachers' satisfaction.

Teachers' introduction and support to VISIR was adequate, contributing to students' engagement and motivation. Some mismatch was found between the learning goals, namely the level/type of competence teachers want students to develop with VISIR and the type of tasks proposed/ implemented. We realize teachers must be extra careful while planning the activities with VISIR in order to diminish this difference.

Finally answering the research question: "According to teachers' perception, which didactical implementation design factors seem to influence students' performance and motivation?" some factors were identified:

- Teacher introduction to VISIR and support during the semester plays an important role in the implementation success.

- Teacher experience with VISIR is very important.

- Teachers should plan VISIR tasks carefully, according to the type of competences they want their students to develop.

\section{ACKNOWLEDGMENTS}

This research work is made within the University of Salamanca PhD Program on Education in the Knowledge Society.

\section{REFERENCES}

[1] A. M. Al-Bahi, M. A. Taha, and E. N. Turkmen, "Teaching and assessing engineering professional skills," Int. J. Eng. Pedagogy, vol. 3, no. S3, pp. 13-20, Jun. 2013

[2] J. E. Froyd, P. C. Wankat, and K. A. Smith, "Five major shifts in 100 years of engineering education," Proc. IEEE, vol. 100, no. Special Centennial Issue, pp. 1344-1360, May 2012.

[3] E. E. Stwine and T. Jungert, "Engineering students' experiences of transition from study to work," J. Educ. Work, vol. 23, no. 5, pp. 417-437, 2010.

[4] C. A. Jara, F. A. Candelas, S. T. Puentes, and F. Torres, "Handson experiences of undergraduate students in automatics and robotics using a virtual and remote laboratory," Comput. Educ., vol. 57, no. 4, pp. 2451-2461, 2011.

[5] J. R. Brinson, "Learning outcome achievement in non-traditional (virtual and remote) versus traditional (hands-on) laboratories: A review of the empirical research," Comput. Educ., vol. 87, pp. 218-237, Sep. 2015.

[6] A. Marques et al., "How remote labs impact on course outcomes: Various practices using VISIR," IEEE Trans. Educ., vol. 57, no. 3, pp. 151-159, Oct. 2014.

[7] J. Ma and J. V. Nickerson, "Hands-on, simulated, and remote laboratories: A comparative literature review," ACM Comput. Surv., vol. 38, no. 3, p. 7, 2006. 
[8] M. Prensky, "Digital natives, digital immigrants part 1," Horizon, vol. 9, no. 5, pp. 1-6, Oct. 2001.

[9] G. Alves et al., "Using VISIR in a large undergraduate course: Preliminary assessment results," in Proc. Global Eng. Educ. Conf. (EDUCON), Apr. 2011, pp. 1125-1132.

[10] A. Stinner, "Contextual settings, science stories, and large context problems: Toward a more humanistic science education," Sci. Educ., vol. 79, no. 5, pp. 555-581, 1995.

[11] R. Koul and T. M. Dana, "Contextualized science for teaching science and technology," Interchange, vol. 28, no. 2, pp. 121-144, Apr. 1997.

[12] G. R. Alves et al., "International cooperation for remote laboratory use," in Contributions to Higher Engineering Education. Singapore: Springer-Verlag, 2018.

[13] J. E. Corter, S. K. Esche, C. Chassapis, J. Ma, and J. V. Nickeson, "Process and learning outcomes from remotely-operated, simulated, and hands-on student laboratories," Comput. Educ., vol. 57, no. 3, pp. 2054-2067, 2011.

[14] J. B. Lopes, Aprender e Ensinar Física [Learning and Teaching Physics]. Lisboa, Portugal: Fundação Calouste Gulbenkin, Fundação Para a Ciência e Tecnologia, 2004.

[15] A. E. Cunha, E. Saraiva, C. A. Santos, F. Dinis, and J. B. Lopes, "Teacher mediation actions and students' productive engagement during the use of computer simulations in physical science classrooms," Procedia Technol., vol. 13, pp. 76-85, Jan. 2014.

[16] (Feb. 11, 2015). [IAOE] Winners of the GOLC Online Laboratory Award. Accessed: 2016. [Online]. Available: http://lists.onlinelists.org/pipermail/iaoe-members/2015-February/000120.html

[17] I. Gustavsson et al., "A flexible instructional electronics laboratory with local and remote lab workbenches in a grid," Int. J. Online Eng., vol. 4, no. 2, pp. 12-16, 2008.

[18] N. Lima, C. Viegas, G. Alves, and F. Garcia-Peñalvo, "VISIR's usage as an educational resource: A review of the empirical research," in Proc. 4th Int. Conf. Technol. Ecosyst. Enhancing Multiculturality (TEEM), Salamanca, Spain, 2016, pp. 893-901.

[19] G. Alves et al., "Spreading remote lab usage a system-A communityA federation," in Proc. 2nd Int. Conf. Portuguese Soc. Eng. Educ. (CISPEE), Vila Real, Portugal, Oct. 2016, pp. 1-7.

[20] T. Deignan, "Enquiry-based learning: Perspectives on practice," Teach. Higher Educ., vol. 14, no. 1, pp. 13-28, 2009.

[21] N. Lima, C. Viegas, A. Marques, G. Alves, and F. García-Peñalvo, "Macro analysis on how to potentiate experimental competences using VISIR," in Proc. 6th Int. Conf. Technol. Ecosyst. Enhancing Multiculturality (TEEM), Salamanca, Spain, 2018, pp. 624-632.

[22] C. Viegas, N. Lima, G. Alves, and I. Gustavsson, "Improving students experimental competences using simultaneous methods in class and in assessments," in Proc. 2nd Int. Conf. Technol. Ecosyst. Enhancing Multiculturality (TEEEM), Salamanda, Spain, 2014, pp. 125-132.

[23] R. M. Salah, G. R. Alves, D. H. Abdulazeez, P. Guerreiro, and I. Gustavsson, "Why VISIR? Proliferative activities and collaborative work of VISIR system," in Proc. EDULEARN, Barceløna, Spain, 2015, pp. 1-10.

[24] L. Cohen, L. Manion, and K. Morrison, Research Methods in Education, 6th ed. London, U.K.: Routledge, 2007.

[25] B. Glaser and A. Strauss, The Discovery of Grounded Theory: Studies for Qualitative Research. New York, NY, USA: Adline, 2012.

[26] C. Sarabando, J. P. Cravino, and A. A. Soares, "Improving student understanding of the concepts of weight and mass with a computer simulation," J. Baltic Sci. Educ., vol. 15, no. 1, pp. 109-126, 2016.

[27] C. Viegas et al., "Impact of a remote lab on teaching practices and student learning," Comput. Educ., vol. 126, pp. 201-216, Nov. 2018.

[28] W. J. Conover, Practical Nonparametric Statistics. New York, NY, USA: Wiley, 1999.

[29] D. Wood and C. O'Malley, "Collaborative learning between peers: An overview," Educ. Psycol. Practise, vol. 11, no. 4, pp. 4-9, 1996.

[30] G. S. Ferreira, J. Lacerda, L. C. Schlichting, and G. R. Alves, "Enriched scenarios for teaching and learning electronics," in Proc. Technol. Appl. Electron. Teach. (TAEE), Bilbao, Spain, Jun. 2014, pp. 1-6. 